\title{
Perdón y justicia en Ana Karenina ${ }^{1}$
}

\section{Forgiveness and Justice in Ana Karenina}

Pues esta ley impuso a los hombres el Cronión: a los peces, fieras y aves voladoras, comerse los unos a los otros, ya que no existe justicia entre ellos; a los hombres, en cambio, les dio la justicia, que es mucho mejor (Hesíodo, 2006, p. 138)2

\section{Lucía María Traverso ${ }^{3}$}

\section{Resumen}

Cuando Alejo Karenina los perdona, ni Ana ni Wronsky comprenden por qué. ¿Es que ellos no se sienten dignos del perdón? ¿O acaso lo ven como algo tan ajeno al campo de la justicia que simplemente no pueden comprenderlo?

¿Es justo perdonar? ¿Va el perdón "más allá de lo justo"? ¿Es posible que lo que resulta "insoportable", cuando uno lleva una vida inmoral, no sea el castigo, sino precisamente el perdón?

Palabras clave: Ana Karenina - Tolstói - Justicia Filosofía del Derecho - Perdón - Misericordia

\section{Abstract}

When Alejo Karenina forgives them, neither Ana nor Wronsky understand why. Is it that they feel unworthy of forgiveness? Or perhaps they think it is something so distant to the field of justice that they simply cannot understand it?

Is it fair to forgive? Is forgiveness "beyond fairness"? Is it possible that what is "unbearable", when one leads an immoral life, is not punishment, but precisely forgiveness?

Key words: Anna Karenina - Tolstói - Justice Philosophy of Law - Forgiveness - Mercy

\section{Derecho / investigación científica}

Citar: Traverso, L. M. (2020). Perdón y justicia en Ana Karenina. Omnia. Derecho y sociedad, 3 (3), pp. 9-26.

1 La autora publica este trabajo en el marco del Proyecto de Investigación "Principales problemas de justicia y su solución en la literatura universal", dirigido por el Dr. Siro M. A. De Martini. Programa lus - Acreditación de Proyectos de Investigaciónn Jurídica. Investigación jurídica aplicada. Facultad de Derecho. UCA. Convocatoria 2019-2021.

${ }^{2}$ Otras traducciones, como la escogida por Gómez Robledo en su obra Meditación sobre la Justicia, ensalzan la superioridad de la justicia en relación a todo lo demás: "Las bestias y los peces y las aves se devoran entre sí. Pero el hijo de Cronos dio a los hombres la Justicia (Diké), y es con mucho lo mejor que tienen" (Gómez Robledo, 1982, p. 16).

${ }^{3}$ Universidad Católica Argentina. Abogada egresada de la Pontificia Universidad Católica Argentina. Doctoranda en Ciencias Jurídicas por la Pontificia Universidad Católica Argentina. Docente adscripta de la Facultad de Derecho de la Pontificia Universidad Católica Argentina. Investigadora IUS en el proyecto "Principales problemas de Justicia y su solución en la literatura universal" de la Facultad de Derecho de la Pontificia Universidad Católica Argentina. luciatraverso@uca.edu.ar 


\section{INTRODUCCIÓN}

A partir de su publicación en 1877, mucho se ha escrito sobre Ana Karenina; se han analizado las cuestiones políticas, las lúcidas descripciones de los personajes, las críticas de Lev Tolstói a la clase aristocrática rusa, el aspecto religioso en Alejo Karenina y en Levine, entre otras grandes temáticas.

La intención de este trabajo es abordar un aspecto que adquiere, en la especial relación entre Alejo Karenina, Wronsky y la misma Ana, un extraordinario relieve: aquel que lleva a Ana al terrible desenlace que es el suicidio.

Cuando Alejo Karenina los perdona, ni Ana ni Wronsky comprenden por qué. Ese conflicto que se vive trágicamente entre los personajes de la obra ha sido receptado por la teoría filosófica y encierra múltiples interrogantes, entre los cuales el primero y decisivo es ¿es justo perdonar? En cualquier caso, ¿cuál es la relación que existe entre perdón y justicia?

En Tolstói esas y otras preguntas, que son su consecuencia posible $y$, a veces, inevitable, adquieren una singular encarnación en diálogos, personajes, conflictos, pasiones desatadas o reprimidas. Como en toda gran obra de arte, los problemas y sus soluciones aparecen llenos de matices, de dudas; de verdad y de error, sí, pero como los vive el hombre real y concreto.

De la mano de sus grandes personajes deberemos plantearnos cuestiones tales como si el perdón es una respuesta que trasciende lo justo aunque sin dejarlo de lado, o si lo que puede resultar insoportable para quien ha llevado una vida inmoral no es la justicia precisa del castigo, sino la grandeza desmesurada del perdón. Y, por fin, si es posible que el suicidio sea la salida de ese laberinto de culpa, castigo y perdón.

Pero antes de tratar estos interrogantes literarios, filosóficos, existenciales-profundamen- te humanos-, señalaremos algunos aspectos relevantes de la vida de Tolstói y sus personajes que nos permitirán iluminar el análisis.

\section{LEV TOLSTÓI Y SU REFLEJO}

Aquel que lleva al papel lo que él sufre es un autor triste; pero se convierte en autor serio cuando nos dice lo que ha sufrido y por qué ahora descansa en la alegría (Nietzsche, 2012, p. 34)

Tolstói escribe en su diario: “... he podido darme cuenta con toda claridad de que la vida desordenada (...) no es otra cosa que la consecuencia de una precoz corrupción del alma" (Tolstói, 2011, p. 15).

Solo tenía 19 años y ya mostraba fuertemente su naturaleza trazada por la moral. A su corta edad ya parecía haberse puesto sobre sus hombros una tarea difícil: "no basta con apartar a la gente del mal, es necesario estimularla hacia el bien" (Tolstói, 2011, p. 15).

Treinta años más tarde, Tolstói publica Ana Karenina. En esta obra desarrolla plenamente las infames consecuencias de una vida desordenada, y busca generar en el lector esperanzas de cambio. Ofrece personajes cuyos caminos son inversos a los de Ana, invitándonos a ver las consecuencias de las elecciones y a optar a través de sus ejemplos.

Tiene que haber un cambio en mi manera de vivir. Pero es necesario que este cambio no sea obra de las circunstancias exteriores, sino del alma. Aquí me hago una pregunta: ¿cuál es el objetivo de la vida humana? Cualquiera que sea la culminación de mis reflexiones, cualquiera que sea el punto de partida, siempre llego a la misma conclusión: el objetivo de la vida humana es contribuir de todas las maneras posibles al desarrollo armónico de lo existente (Tolstói, 2011, p. 17). 
Esta frase extraída de sus diarios parece tener dos aspectos importantes: en la primera parte reconocemos que quizás la inspiración para el personaje de Ana haya sido el joven Tolstói que busca una forma de salir de su propio laberinto, pero muy consciente de que ningún cambio externo valdría; solo un cambio en su alma podría salvarlo. Y en la segunda parte de la frase podemos ver esa "misión": contribuir al desarrollo armónico de lo existente. ¡Qué misión noble!

Parecería que lo más valioso del diario de Tolstói (2011) es que genuinamente está organizado de tal forma que permite que el lector vaya "madurando" con él. Escribe lo que él llama reglas, y las hay para múltiples tareas: "reglas para el desarrollo de la voluntad corporal y afectiva" (p. 21); "reglas para someter a la voluntad el sentimiento de amor" (p. 23); "reglas para el desarrollo de la facultades intelectuales" (p. 26); "reglas para el desarrollo de los sentimientos elevados y la destrucción de los sentimientos bajos, en otras palabras, reglas para el desarrollo del amor y el aniquilamiento del sentimiento de amor propio" (p. 27), entre otras.

Si bien no podríamos jamás simplificar la cuestión hasta decir que Ana Karenina también es una "guía de comportamiento" como sus propios diarios, sí constituye un ejemplo, como decíamos antes, de las distintas opciones y caminos que nos presenta la vida. Es, quizás, una forma literaria de comprobar que llevar una vida virtuosa trae menos "complicaciones".

En la última carta que el escribe antes de morir, en 1910, le dice a su hijo:

Esas ideas que has asimilado sobre el darwinismo, la evolución y la lucha por la existencia no te explicarán el sentido de tu vida ni te darán una guía para tus actos, y una vida sin una explicación de su significado y su sentido, y sin la guía inalterable que de ella se desprende, es una existencia lamenta- ble. Piénsalo. Te digo esto en el umbral de la muerte, porque te quiero. Intentad tranquilizar a mamá, a quien compadezco y amo sinceramente, vuestro padre que os quiere, Lev. (Tolstói, 2008, p. 794).

Es inspirador saber que la forma en la que Tolstói elige despedirse de su familia es, también, la manera en la que decide terminar el libro. El personaje de Levine (a quien la mayoría de los intérpretes identifica como "el personaje de Tolstói") concluye en los últimos momentos que la búsqueda importante y el sentido único de la vida debe ser siempre la búsqueda del bien.

\section{EVOLUCIÓN DE LOS PERSONAJES}

El 24 de octubre de 1889, más de una década después de la publicación de Ana Karenina, Tolstói escribe:

Pensé: Lo que me ha conducido a una conciencia religiosa verdadera, inquebrantable, es haber reconocido lo que la vida tiene de absurdo y de miserable, y haberlo reconocido no a través de la razón, sino a través de un sentimiento de todo el ser. Hay una diferencia entre reconocer con la inteligencia y ser llevado al borde del abismo, y horrorizarse al verlo. Me parece que sólo esto puede llevar a una fe inquebrantable: sólo cuando uno ha comprobado que todos los caminos, salvo el único verdadero, tienen algo de pernicioso, se coloca imperturbablemente en el camino correcto. Así me sucedió a mí y así, me parece, debe sucederle a todo el mundo (Tolstói, 2011, p. 323).

La historia de Tolstói entonces es también la historia de Ana, ella conoce el abismo -y, por desgracia, no puede salir de él-. Tenemos la

Omnia. Derecho y sociedad, núm. 3, 2020: 9-26 
oportunidad de ver, a través de los personajes, las distintas posibilidades que nos plantea la vida. Así, podemos experimentar con ellos y evitarnos los caminos oscuros del error.

Kitty, hermana de Dolly y cuñada de Esteban, percibía en Ana "una mujer sencilla en su trato e incapaz de ocultar nada; pero al mismo tiempo, veía en ella un mundo superior (...) y lleno de poesía" (Tolstói, 2000, p. 92). Ana no solo es, al principio de la obra, una mujer casada, con un hijo adorado y alegre, sino que también representa un "ejemplo" (tanto moral como social) para su hermano Esteban. A medida que avanzan los capítulos, vemos cómo esta figura se aleja lentamente de lo bueno y actúa cada vez peor.

Recién llegada de vuelta de su viaje a Moscú, en donde había conocido a Wronsky, Ana pierde, por unos instantes, esa nota de ternura hacia su marido y su hijo; “... también aquel niño, como su esposo, produjo a Ana cierta decepción. A través de su imaginación lo veía mejor de lo que era en realidad. (...) Aquel día, no sabía por qué, sólo veía defectos" (Tolstói, 2000, p. 92).

Ana entonces comienza a dudar de sus propios sentimientos:

... es una buena persona - se decía Ana al regresar a su habitación, como si tratara de defenderlo ante alguien que afirmaba que era imposible amarlo-. Es recto, noble $y$, además, tiene un gran cargo y lo desempeña a la perfección... Pero sus orejas parecen más largas que antes... (Tolstói, 2000, p. 97).
No podemos dejar de señalar lo que nos anticipa Tolstói en la declaración de amor de Wronsky, que luego será la que desencadena la relación extramatrimonial que hará caer en desgracia a los amantes. Dice Wronsky:

... puedo darle mi persona, toda mi persona, y también todo mi amor... Ni con el pensamiento me puedo separar de usted. No veo probabilidad alguna de que ni usted ni yo podamos tener calma en el futuro. Lo que veo es la desesperación, el infortunio... O la felicidad... (Tolstói, 2000, p. 122).

Lo que debemos preguntarnos, entonces, es si es posible vivir felizmente realizando actos moralmente malos ${ }^{4}$ que, como tales, dañan necesariamente a otros. Parece más oportuno inclinarnos por la otra posibilidad que se nos presenta en forma de augurio: desesperación e infortunio. Esto es algo que comprueba meses más tarde: "Wronsky, por su parte, aunque había realizado sus más caros deseos, no era completamente feliz. (...) pronto empezó a sentir cierto hastío. Advirtió que en su alma germinaba el deseo de desear, es decir, la tristeza" (Tolstói, 2000, p. 350).

Ante una visita de Wronsky en casa de Ana, antes de que se conociera públicamente el amorío, vemos cómo los personajes perciben la desviación moral en su comportamiento:

... la presencia del niño ${ }^{5}$ producía a Wronsky y a Ana la sensación del navegante que ve con horror -al observar las ciegas indica-

\footnotetext{
${ }^{4}$ Marzie señala que en las obras de Tolstói normalmente se concluye que solo se puede vivir felizmente llevando una vida moral y religiosa. "В своих произведениях Толстой обычно делает такой вывод - только на религиозной нравственной основе можно обрести счастье в жизни" (la traducción es nuestra). Marzie, 2007, Pazhuhesh-e Zabanha-ye Khareji, N. 35, Special Issue, Rusia, 2007, pp. 91-101.

Recuperado de https://jor.ut.ac.ir/article_18071_bfe83c57fcdec5289da5326584283b75.pdf (consultado en agosto de 2018).

${ }^{5}$ Se refiere a Sergio, el hijo de Ana.
} 
ciones de la brújula—, que la dirección que sigue está muy lejos de ser la conveniente $y$, sin embargo, es incapaz de detenerse, de modo que a cada minuto que pasa se aparta más del rumbo que debería seguir. Lo cual equivale a juzgar irremediable la propia perdición (Tolstói, 2000, p. 158).

Hacia la mitad de la obra, Ana se entera de que está embarazada de Wronsky: "—estoy encinta — dijo entonces ella, muy bajito y lentamente" (Tolstói, 2000, p. 160).

Luego Ana está tan inmiscuida en su propio accionar que no puede pensar en nadie más que en sí misma.

Ana se animó de pronto al acordarse, por primera vez en aquella mañana, de la existencia de su hijo. (...) Al acordarse de Sergio, Ana vio el modo de evadirse del callejón sin salida en que se encontraba. Pensó en las madres que dedicaban enteramente su existencia a sus hijos, y entonces comprendió que en su vida había algo muy importante y sin relación a su problema. Ocurriera lo que ocurriera, ella no abandonaría jamás a su hijo (Tolstói, 2000, p. 204).

Pero también vemos a Ana fallar en esto que se había propuesto: “... al mes siguiente, Alejo Alejandrovitch se quedaba en su casa sin más compañía que la de su hijo Sergio. Y entre tanto, Ana y Wronsky se marchaban lejos de San Petersburgo sin pensar para nada en el divorcio" (Tolstói, 2000, p. 330).

Lo que viene después en la vida de Ana es una seguidilla de reproches a su amante, recuerdos negativos de su marido, pensamientos tristes sobre su hijo y la sensación de ser una extranjera en la sociedad que antes tan bien la acogía. Como señala Wronsky: "-Todo te amarga la vida: la sociedad, tu hijo, tu espo- so" (Tolstói, 2000, p. 161). En palabras de Alejo: "Ana es una mujer sin sentimientos, sin honor y sin fe" (Tolstói, 2000, p. 198).

Aparece, por un momento, cuando está enferma tras el parto de su hija, un destello de iluminación y de salvación. Le envía una carta a Alejo para que vaya a visitarla. "Te ruego que vengas, moriré más tranquila si me perdonas" (Tolstói, 2000, p. 300). Ese ruego de misericordia, que analizaremos posteriormente, es el eje central del libro. A partir de ese pedido, en caso de que se lo conceda, Ana tendrá dos opciones: o retomar el camino del bien o ahogarse en el mal.

Alejo Karenina hace lo que podríamos llamar "el camino inverso" al de Ana. Si bien empieza siendo un hombre "respetado" en sociedad, en la privacidad de su hogar era malhumorado y amargo: "Alejo regresó a su casa a eso de las cuatro, y, como solía suceder, no tuvo tiempo para saludar a su esposa" (Tolstói, 2000, p. 95). Pero "solamente los íntimos de Alejo Alejandrovitch sabían que este hombre, tan frío y tan juicioso, tenía una debilidad que estaba en contradicción con su carácter: no podía ver ni oír llorar a los niños ni a las mujeres" (Tolstói, 2000, p. 197).

Mientras que su esposa se aleja de lo deseable, él trata cada vez con más intensidad atraerla hacia el camino correcto:

... mi obligación está bien clara. Como jefe de familia, debo dirigir a mi esposa (...) he de hacerle ver el peligro que yo veo y defenderla contra él, (...) primero le hablaré del significado y valor de la opinión pública, luego, de la importancia y sentido religioso del matrimonio; a continuación, si es preciso, de la desdicha que su conducta puede ocasionar a su hijo, y, finalmente, de la desgracia que proceder puede suponer para ella (Tolstói, 2000, p. 127). 
Para los rusos ortodoxos (como los personajes de la obra, y como el mismísimo Tolstói), la confesión es como un "remedio" para llevar al enfermo de nuevo hacia la sanidad. Cuando se perdona, se otorga esta medicina y se le permite al enfermo que deje de vivir en esa situación. Cuando Dios nos perdona, nos sana. Los hombres, siguiéndolo a Él, debemos perdonar también para ayudar al enfermo.

La confesión no se debe observar desde la perspectiva del castigo y de la justificación sino, más bien, como alivio y curación. El hombre solo es incapaz de conseguir la salvación (justificación) por un esfuerzo propio -llámese "confesión" o cualquier otro nombre-, por lo que la penitencia jamás será un medio de expiación sino una medicina, y la confesión una operación quirúrgica que procura llevar al enfermo hacia la plena sanidad. Se trata, entonces, de actitudes positivas y no negativas: no de quebrantar el muro que separa al pecador de Dios, sino de construir un puente que lo comunique con Él6.

No podemos dejar de destacar que cuando finalmente se dirige a su esposa para compartirle sus reflexiones, Alejo no puede evitar señalar:

... de tus sentimientos, tu propia conciencia será el mejor juez; pero estoy obligado ante Dios, por tu bien y por el mío, a velar por tus deberes y recordártelos. Es Dios, no los hombres, quien ha unido nuestras vidas. Romper esta unión sería un crimen, y este crimen merecería un castigo proporcionado a él (Tolstói, 2000, p. 130).
Aquí vemos una clara expresión de la justicia en el pensamiento de Alejo: si Ana, con su accionar, está cometiendo un crimen, entonces merece una sanción, un castigo, una retribución.

Alejo, meses antes de poder perdonar, pudo ser justo:

... cumplo con las leyes divinas, no sólo no rechazo a la mujer culpable, sino que le doy ocasión para rehabilitarse. Además, y aunque esto sea muy doloroso para mí, yo mismo haré cuanto esté en mi mano por corregirla (Tolstói, 2000, p. 200).

Pero debemos insistir en los términos elegidos; solo pudo ser justo.

Sobre la diferencia entre justicia y misericordia hablaremos posteriormente, especialmente cuando trabajemos sobre la parábola del hijo pródigo. Pero, al momento de evaluar la evolución de Alejo, no podemos dejar de destacar que él pasó de ser un hombre justo a ser un hombre misericordioso, elevándose.

[Alejo Alejandrovitch] había perdonado sin reservas a su esposa y se compadecía de sus sufrimientos. También había otorgado el perdón a Wronsky, sobre todo después de enterarse de su desesperada tentativa. Compadecía a su hijo y se reprochaba a sí mismo no haberse preocupado por él. Y hacia la recién nacida experimentaba no sólo un sentimiento de compasión, sino verdadera ternura (Tolstói, 2000, p. 312).

Debemos señalar que el término elegido por Tolstói es de suma riqueza: San Agustín (1975) ha escrito que "(...) la misericordia es

\footnotetext{
${ }^{6}$ Samaan, I. Penitencia y confesión. Recuperado de http://iglesiaortodoxa.org.mx/informacion/1111/11/penitencia-yconfesion/ (consultada en enero de 2018).
} 
la compasión de la miseria ajena en nuestro corazón, por la cual nos compele a socorrer si podemos" (p. 253).

\section{LA JUSTICIA Y EL PERDÓN ${ }^{7}$}

No hay mayor miseria que el pecado. No hay por ello mayor misericordia que el perdón (De Martini, 2013, p. 46)

Es inhumano bendecir cuando nos han maldecido (Nietzsche, 2008, p. 98)

Si nos remitimos al pensamiento clásico, podemos observar que para poetas como Hesíodo, Solón ${ }^{8}$, Sófocles ${ }^{9}$, Arquíloco ${ }^{10}$, la ruptura del orden trae consigo males para los hombres. En Los trabajos y los días, Hesíodo (2006) señala:

Preferible es el camino que (...) conduce hacia el recto proceder; la justicia termina prevaleciendo sobre la violencia, y el necio aprende con el sufrimiento. (...) Cuando la Diké es violada, se oye un murmullo allí donde la distribuyen los hombres devoradores de regalos e interpretan las normas con veredictos torcidos. Aquella va detrás quejándose de la ciudad y de las costumbres de su gen- te, envuelta en niebla, y causando mal a los hombres que la rechazan y no la distribuyen con equidad. Para aquellos que dan veredictos justos a forasteros y ciudadanos y no quebrantan en absoluto la justicia, la ciudad se hace floreciente y la gente prospera dentro de ella; la paz nutridora de juventud reside en su país y nunca decreta contra ellos la guerra espantosa Zeus de amplia mirada. Jamás el hambre ni la ruina acompañan a los hombres de recto proceder, sino que alternan con fiestas el cuidado del campo. (...) Las mujeres dan a luz niños semejantes a sus padres y disfrutan sin cesar de sus bienes. No tienen que viajar en naves y el fértil campo les produce frutos (Hesíodo, 2006, p. 136).

El buen orden es excelente para los mortales, el desorden, en cambio, funesto:

... a quienes en cambio sólo les preocupa la violencia nefasta y las malas acciones, contra ellos el Crónida Zeus de amplia mirada decreta su justicia. Muchas veces hasta toda la ciudad carga con la culpa de un malvado cada vez que comete delitos o proyecta barbaridades. Sobre ellos desde el cielo hace caer el Cronión una terrible calamidad, el

\footnotetext{
7 "El perdón, entonces, es sobre todo un don. Por ello ha podido decirse que la esencia del perdón es la gratuidad. Se trata de un regalo que busca satisfacer una necesidad grave y profunda del ofensor". (De Martini, 2013, p. 233).

8 "Ni siquiera respetan los augustos cimientos de Diké, quien, silenciosa, conoce lo presente y el pasado, y al cabo del tiempo en cualquier forma viene a vengarse". Solón. Eunomía. Traducción de Carlos García Gual. En: Zecchin de Fasano, G. C. (2014). “El concepto de Eunomía: ¿Odisea en Solón?»

9 "Creonte: Diré lo que traigo del dios. El rey Apolo nos ordena borrar la mancha que ha caído en este país, extirparla, lejos de mantenerla, por temor a que sea inextirpable. (...) Estrofa II: ;Oh, Dioses! Yo sufro males innumerables; mi pueblo entero languidece (...) Los frutos de esta tierra ilustre no maduran; las mujeres no paren y sufren dolores lamentables (...) Antisfrofa II: La ciudad está agotada por los funerales innúmeros; la multitud no llorada y que da la muerte yace sobre la tierra, y las jóvenes casadas y las madres de blancos cabellos, prosternadas aquí y allá sobre las gradas de cada altar, piden con alaridos y lamentos el fin de sus males deplorables". (Sófocles, 2012, p. 116).

10 "Ni debes pavonearte ante el mundo como vencedor ni hundirte y lamentarte como vencido; alégrate con lo que es digno de alegría, no te rindas con exceso ante la desventura, conoce el ritmo que mantiene a los hombres en sus límites". Arquíloco, fragmento 67 a, 7. En Jaeger, 2012, p. 126.
} 
hambre y la peste juntas, y sus gentes se van consumiendo. Las mujeres no dan a luz y las familias menguan por determinación de Zeus Olímpico (Hesíodo, 2006, p. 137).

¿Es posible, entonces, que una persona que actúa mal y que rompa el orden pueda ser feliz? Si nos atenemos a un concepto de felicidad como plenitud y búsqueda de perfección ${ }^{11}$ del hombre, entonces parece evidente que la respuesta es no ${ }^{12}$.

En efecto, Ana considera que la respuesta justa ante su actuar inmoral es un castigo, retributivo, penoso, como modo de recomponer el orden roto.

Pero, entonces, debemos adentrarnos en una pregunta aún más grande; ¿es el perdón justo?

Séneca ${ }^{13}$ (1949) sostenía que el que perdona va en contra de lo justo. Pero el cristianismo nos dice lo contrario: ser justo es perdonar.

Cristo subraya con tanta insistencia la necesidad de perdonar a los demás que a Pedro, el cual le había preguntado cuántas veces debería perdonar al prójimo, le indicó la cifra simbólica de "setenta veces siete", queriendo decir con ello que debería saber perdonar a todos y siempre (Juan Pablo II, Dives in Misericordia, 1980, 14).

Santo Tomás escribe:
Dios, al obrar misericordiosamente, no actúa contra sino por encima de la justicia. Ejemplo: Si a quien se le deben cien denarios se le dan doscientos, quien hace esto no es injusto, sino que obra libre y misericordiosamente. Lo mismo sucede cuando se perdonan las ofensas recibidas. Pues quien algo perdona, algo da. Por eso el Apóstol, al perdón lo llama don cuando dice en Ef 4,32: Daos unos a otros como Cristo se dio a vosotros. Queda claro, así, que la misericordia no anula la justicia, sino que es como la plenitud de la justicia (Santo Tomás, II-II, q.21, a.3.).

Es notable que el primer vestigio que podemos encontrar del perdón en la obra no esté vinculado con Ana, sino con Dolly y Esteban. En rigor, Ana llega a Moscú con la única finalidad en mente de ayudar a su hermano a ser perdonado por su esposa tras haberla engañado (no por primera vez) con la niñera de los niños.

Ana trata de convencer a Dolly de que este engaño no significa falta de cariño, que ella conoce el tipo de hombre que es su hermano, y que "tiene una facilidad extraordinaria (...) para dejarse llevar por las tentaciones; pero también para arrepentirse profundamente (...) Dolly, perdónalo" (Tolstói, 2000, p. 63).

Podemos ver dos cosas en esta cita: por un lado, pareciera que el hecho de que Esteban haya cometido esa falta por un vicio en su voluntad y no "haya pensado" en las consecuen-

\footnotetext{
11 "Es claro que debe definirse la felicidad diciendo que es el acto de una vida completa conforme a la completa virtud". (Aristóteles, 1948, p. 133).

12 La miseria se opone a la felicidad (De Aquino, T., Suma Teológica, II-II, q.30, a.1).

${ }^{13}$ Cf. Fraile, 1976, T. 1, p. 618.

Como explica De Martini (2013): «Las palabras latinas que traducimos por "perdón" o "perdonar" no cambiaron inmediatamente su significado. Continuaron significando la remisión de una deuda, falta, ofensa. Sin embargo, lo que cambió radicalmente fue la cosa, esto es, su valor, su significado moral. Un pensador de la talla de Séneca, en tantos aspectos cercano al cristianismo, podía todavía afirmar que "el sabio (...) no perdona porque quien perdona omite algo que debió ser hecho"»». (p. 25).
} 
cias sería un motivo importante por el que debería perdonarlo. Si él hubiera actuado con intenciones de lastimar, entonces no sería tan merecedor del perdón. Pero también es destacable que en las palabras de Ana parecería que todo aquel que se arrepiente merece perdón.

Esa inferencia es muy cristiana, dado que Dios es quien nos perdona cuando estamos arrepentidos $^{14}$.

En el Antiguo Testamento la misericordia y la justicia humanas están vinculadas de un modo estrecho, íntimo, necesario, con la misericordia y justicia de Dios. De tal modo, supone una cierta dosis de arbitrariedad racionalista pretender analizar sus contenidos y, más aún, vincularlos, prescindiendo del plano paradigmático divino (De Martini, 2013, p. 102) ${ }^{15}$.

De hecho, la nota que le manda a Esteban para decirle que vuelva a la hora de comer dice simplemente: "Ven. La bondad de Dios es infinita" (Tolstói, 2000, p. 64). No necesita ser más explícita para que se entienda que está perdonado.

Santo Tomás de Aquino, en su comentario al salmo 50, escribe que la misericordia de Dios no es otra cosa que su bondad orientada al rechazo de la miseria ${ }^{16}$. Por esto mismo, decir que la bondad de Dios es infinita no es más que decir que ha sido perdonado.

Juan Pablo II escribe en la encíclica Dives in misericordia (1980): “La primacía y la superiori- dad del amor respecto a la justicia (lo cual es característico de toda la revelación) se manifiestan precisamente a través de la misericordia" (Dives in misericordia, 4).

"El amor, conteniendo la justicia, abre el camino a la misericordia, que a su vez revela la perfección de la justicia" (Dives in misericordia, 8). Es interesante cómo, aunque la misericordia va "más allá" de la justicia, la perfecciona.

Es obvio que una exigencia tan grande de perdonar no anula las objetivas exigencias de la justicia. La justicia rectamente entendida constituye por así decirlo la finalidad del perdón. En ningún paso del mensaje evangélico el perdón, y ni siquiera la misericordia como su fuente, significan indulgencia para con el mal, para con el escándalo, la injuria, el ultraje cometido. En todo caso, la reparación del mal o del escándalo, el resarcimiento por la injuria, la satisfacción del ultraje son condición del perdón (Dives in misericordia, 14).

Evidentemente, es condición necesaria para que el perdón sea justo que el perdonado haga todo lo que esté a su alcance para no seguir perpetuando aquella situación que causa un daño.

Alejo, como veíamos anteriormente ${ }^{17}$, pudo ser justo "evaluando" que lo más conveniente (de acuerdo con las leyes divinas) era no otorgarle a Ana el divorcio, sino ayudarla a que se rehabilitara.

\footnotetext{
${ }^{14}$ San Francisco de Sales (1999), sobre la justicia y la misericordia de Dios, dice que ambas son "igualmente amables y maravillosas en sí (...) pero como los efectos de la justicia nos resultan ásperos y llenos de amargura, Él los mitiga siempre con la mezcla de su misericordia". (p. 504).

${ }^{15}$ Cf. Pétré, 1948, p. 230.

16 "Unde nihil aliud est haec Dei misericordia, nisi bonitas relata ad depellandam miseriam. Ergo cum considero quod bonitatis miseriam repellere est proprium, et tamen est ipsa bonitas, confidenter ad misericordiam recurro". Comentario al salmo 50 .

${ }^{17}$ Consultar apartado "Evolución de los personajes".
} 
Pero, como vimos, el perdón es un acto de misericordia, no de justicia.

Hay que recordar en este punto la parábola del hijo pródigo. Allí se nos narra la historia de un padre y sus dos hijos. El hijo menor le pide a su padre que reparta los bienes sólo para irse a otra provincia lejana y dilapidarlos. Cuando se queda sin nada y comienza a trabajar, pero casi muriendo de hambre, recuerda a los jornaleros de su padre que tienen lo suficiente para comer, y decide volver a la casa de su padre para pedirle que lo tome de vuelta. Mientras lo ve volver, su padre "conmovido" corre y se echa sobre su cuello para besarlo. El padre, al mismo tiempo que el hijo le mostraba su arrepentimiento ${ }^{18}$, les dice a sus siervos:

Daos prisa. Traed el mejor traje y vestidle; ponedle un anillo en el dedo y calzadle unas sandalias. Traed el novillo cebado, matadlo, y comamos y celebremos una fiesta, porque este hijo mío había muerto y ha vuelto a la vida; se había perdido y ha sido hallado (Lucas 15, 12).

El hijo mayor, al regresar, oye la música y pregunta a uno de los criados qué es lo que está sucediendo. No quiere entrar a la fiesta. El padre le ruega que entre pero el hijo mayor le contesta:

... hace muchos años que te sirvo y jamás dejé de cumplir una orden tuya. Sin embargo, nunca me has dado un cabrito para tener una fiesta con mis amigos, y ahora que ha venido ese hijo tuyo, que ha devorado tu hacienda con prostitutas, has matado para él el novillo cebado.

Y el padre explica: "Hijo, tú siempre estás conmigo, y todo lo mío es tuyo. Pero convenía celebrar una fiesta y alegrarse, porque este hermano tuyo había muerto y ha vuelto a la vida, se había perdido y ha sido hallado" (Lucas 15, 11-31).

El hijo mayor no pide otra cosa distinta a la justicia: ¿Cómo puede ser, padre, que mi hermano - aquel hijo tuyo-, habiéndose comportado como se comportó, merezca una fiesta y no un castigo? Y la respuesta del padre es simplemente la misericordia. No necesita más que verlo para perdonarlo; corre y lo besa, haciendo nacer de dentro de él ese amor inspirado por el arrepentimiento de su hijo.

Ana le ruega ${ }^{19}$ a Alejo:

Sólo te pido una cosa, que me perdones, que me perdones (...) Ya sé que soy culpable, pero mi aya me contó que hubo una santa..., ¿cómo se llamaba...?, una santa que había sido peor que yo (...) No. Tú no puedes perdonarme. Sé muy bien que no soy digna de tu perdón (Tolstói, 2000, p. 304).

Ella misma se debate entre el perdón y la justicia; al no sentirse "digna" de perdón, ella está utilizando criterios de justicia; ha causado un daño, entonces merece un castigo, no un bálsamo.

\footnotetext{
${ }^{18}$ El hijo menor le dice: "no merezco ser llamado hijo tuyo, trátame como a uno de tus jornaleros", "he aquí nuevamente la idea común de justicia, aquella que se basa en los merecimientos, en el mérito y demérito, la de la igualdad, la de la exacta proporción. El hijo ha hecho algo malo, ha pecado "contra el cielo" y contra su padre. Se ha mostrado indigno de ser el hijo de su padre y, por tanto, en estricta justicia, no merece ya ser considerado como hijo. (...) En términos de justicia, ya no debe ser considerado hijo. Ha perdido la dignidad de tal" (De Martini, 2013, p. 155).

${ }^{19}$ Sobre la importancia de pedir perdón, cf. Burggraf, 2007. Recuperado de http://www.llar.eu/files/Convivir_en_el_matrimonio.pdf
} 
Como citábamos antes, la misericordia (y el perdón) se desprenden del amor. No hay nada más amoroso que perdonar. Alejo "había adoptado como norma de vida los preceptos cristianos, pero no había creído nunca en Áquel que ordenaba perdonar y amar a los enemigos. (...) Ahora estaba lleno de sentimientos de perdón" (Tolstói, 2000, p. 304). Como señala Babushkina (2016), Alejo, como verdadero cristiano ${ }^{20}$, sucumbe ante un generoso sentimiento que lo envuelve: el perdón. Este sentimiento le brota desde adentro ${ }^{21}$ como el amor ${ }^{22}$.

Alejo le explica a Wronsky:

... le confieso que el deseo de vengarme de usted y de ella me acosaban sin cesar. (...) Es más, deseaba su muerte. Sin embargo... - Hizo una pausa cual si temiera descubrir sus más íntimos sentimientos, y al fin continuó-: Sin embargo, al verla, la perdoné. El sentimiento de perdón me ha abierto los ojos, (...) Una sola cosa pido al señor: que no me arrebate la alegría de perdonar (Tolstói, 2000, p. 306). ${ }^{23}$

\section{EL PERDÓN INSOPORTABLE ${ }^{24}$}

Después de ser otorgado el tan esperado perdón, Ana se empieza a sentir incómoda con su situación de perdonada: "una vez pasado el período de tensión producido por la proximidad de la muerte, Alejo Alejandrovitch empezó a notar que Ana le temía, que se sentía cohibida y avergonzada en su presencia" (Tolstói, 2000, p. 312).

Algo similar sucede con Wronsky, el amante de su esposa, a quien Alejo también perdona:

Wronsky se levantó (...) mirando a Karenina con una expresión llena de respeto. No comprendía bien los sentimientos de $\operatorname{Alejo}^{25}(\ldots)$ pero estaba seguro de que se hallaba frente

${ }^{20}$ Babushkina, I. S. "И Алексей Александрович, как истинный христианин, поддается великодушному чувству, охватившему его", en El problema de la elección de camino, Ministerio de Educación y Ciencia de la Federación de Rusia. Universidad Federal de los Urales, Instituto de Filología, Cultura y Comunicación Intercultural - Departamento de Literatura. (la traducción es nuestra).

${ }^{21}$ Es interesante esta imagen que introduce Tolstói en la que Alejo está lleno de sentimientos de perdón, haciendo parecer que este perdón le nace desde adentro de las entrañas. Cuando nos remitimos a las palabras hebreas que simbolizan la misericordia en el antiguo testamento, uno de los términos que aparece es Rahamín, que "proviene de rehem, el cual designa las vísceras y, en particular, el regazo, la matriz, el seno materno (...). Casi lo físico de la misericordia de Dios" (De Martini, 2013, p. 60).

22 "Amor más fuerte que el pecado", no cesa de proclamar la iglesia. Cf. por todos, Testa, 1981, p. 21.

${ }^{23}$ En su idioma original, Tolstói escribe: "la felicidad del perdón”; “И счастье прощения открыло мне мою обязанность. Я простил совершенно. Я хочу подставить другую щеку, я хочу отдать рубаху, когда у меня берут кафтан, и молю бога только о том, чтоб он не отнял у меня счастье прощения! - Слезы стояли в его глазах, и светлый, спокойный взгляд их поразил Вронского". (Tolstói, 2014, p. 537).

${ }^{24}$ Parecería que, por ser un regalo de semejante envergadura, el perdón es siempre una oportunidad de recuperación y de "empezar de nuevo". Pero, ¿qué pasaría si el perdón se vive como un recordatorio de la propia condición de pecador, de miserable?

${ }^{25}$ En el original, Tolstói (2014) еscribe: “Он не понимал чувства Алексея Александровича. Но он чувствовал, что это было что-то высшее и даже недоступное ему в его мировоззрении", "[Wronsky] No entendía los sentimientos de Alexey Aleksandrovich. Sintió que era algo superior e incluso inaccesible para su concepción del mundo" (p. 538) (la traducción es nuestra). 
a algo sumamente elevado y muy superior a lo que es corriente entre los hombres (Tolstói, 2000, p. 307).

Después de su diálogo con Alejo Alejandrovitch, Wronsky salió de la casa, pero se quedó en la terraza, donde permaneció inmóvil largo rato sin darse exacta cuenta del lugar en que se hallaba (...). Se sentía humillado, culpable, ruin, y advertía que no podía borrar de su conciencia aquella mancha. Se veía fuera de aquel camino por el que había avanzado siempre con tanto orgullo (Tolstói, 2000, p. 307).

Después de que Alejo fuera misericordioso con él, él se supo miserable. Comprendió que

... aquel marido engañado al que hasta entonces había visto como un ser despreciable, como un simple y ridículo obstáculo surgido ante su felicidad, alcanzó de improviso a sus ojos un extremo de bondad envidiable, y desde este momento ya no lo consideró como un ser irrisorio, hipócrita y perverso, sino como una persona sencilla, dotada de una bondad excepcional y merecedora del mayor respeto (Tolstói, 2000, p. 307).

Se sintió inferior, humillado y avergonzado de sí mismo.

Santo Tomás escribe, en relación con la misericordia: "entre todas las virtudes que miran al prójimo, la mayor es la misericordia (...), pues atender a las necesidades de otros es, en este aspecto, del superior y del mejor" (Santo Tomás, II-II, q.30, a.4.). De igual forma, Wronsky se siente peor e inferior, consciente de su pequeñez y de sus faltas. Alejo, a quien él veía como su peor enemigo, había sido capaz de ser misericordioso con él. ¿Es que acaso pensó que no merecía ese perdón? ¿Consideró que ese perdón, que agrandaba el concepto de justicia, elevándolo, lo hacía más pequeño?

Al percatarse de todo esto, Wronsky hubo de advertir también que su situación había cambiado repentinamente. Veía claramente la grandeza moral de Karenina frente a la mezquindad de su propia alma; veía que aquel marido engañado se comportaba generosamente a pesar del dolor que lo afligía, y, en cambio, él se sentía pequeño en su engaño (Tolstói, 2000, p. 307).

La realidad es que "el hombre misericordioso es superior, entonces, porque socorre a quien lo necesita (...) servir al prójimo necesitado es participar de la misión real de Cristo, es cumplir con la vocación y misión del ser humano redimido" (De Martini, 2013, p. 184).

Wronsky debería sentirse sano, limpio, alegre y agradecido de haber sido perdonado, de volver a ser un hombre y no solo un pecador. Como señala Juan Pablo II:

... la misericordia - tal como Cristo nos la ha presentado en la parábola del hijo pródigo - tiene la forma interior del amor, que en el Nuevo Testamento se llama agapé. Tal amor es capaz de inclinarse hacia todo hijo pródigo, toda miseria humana y singularmente hacia toda miseria moral o pecado. Cuando esto ocurre, el que es objeto de misericordia no se siente humillado, sino como hallado de nuevo y "revalorizado" (Dives in misericordia, 6).

En efecto,

... aquél que perdona y aquél que es perdonado se encuentran en un punto esencial, que es la dignidad, es decir, el valor esencial del hombre que no puede dejarse 
perder y cuya afirmación o cuyo reencuentro es fuente de la más grande alegría (Dives in misericordia, 14).

Sin embargo, Wronsky termina por sentirse solo, confundido e inferior.

Después de perdonar a Ana, Alejo se encuentra conversando con la condesa Lidia que le dice: "no es usted el que ha realizado el acto sublime de perdonar a su esposa, acto que todos admiramos, sino Él, Él, que está en su corazón" (Tolstói, 2000, p. 384). Si bien es cierto que toda misericordia humana es reflejo de la misericordia divina, no hay que olvidar que "todos los hombres somos llamados a ser misericordiosos" (De Martini, 2013, p. 184).

Reflexiona Meek (2012):

... todo el dominio que tiene Tolstói sobre tiempo, espacio y lenguaje se sintetizan en un momento hacia la mitad del libro. El marido separado de Ana, un ministro de gobierno seco y rígido, y su amante Wronsky, un hermoso joven oficial de caballería, se encuentran junto a la cama donde yace Ana enferma después de dar a luz a la hija de Wronsky. En duelo y avergonzado, Wronsky cubre su cara con sus manos. Ana ordena a su marido (que también está llorando), que mueva las manos de su amante para descubrir su cara. Con ese gesto, Ana genera una reversión en el estatus de esos dos hombres. Wronsky, que había despreciado a Karenina por no querer pelear en duelo, ahora se encontraba humillado y deshonrado; Karenina, inundado con misericordia y perdón para todos, se gana de nuevo el respeto de Ana. En ese momento, con Ana aparentemente muriendo, la transformación es real. Pero el tiempo cambia, y la antigua realidad vuelve. Ana se mejora y odia a Karenina más que nunca por su perdón. Wronsky recupera su honor con su intento de suicidio (falla). El camino de la destrucción de Ana se reanuda. En la novela no hay puntos de inflexión, solo puntos, y personajes viajando a través de ellos ${ }^{26}$.

Parece ser que recibir un perdón que no creyó merecido hizo caer a Ana en una profunda desesperación. Ella sabía que su actuar era injusto, inmoral, pero consideraba que este actuar no la dañaba. Como señala Tolstói (2004): "la salvación y el castigo de un hombre que no vive regularmente consiste en el hecho de poder cegarse para no ver su desastrosa situación" (p. 83). Antes de enfermar, Ana sostuvo: "no estoy arrepentida de lo que he hecho. ¡No y mil veces no! Si hubiese de volver a empezar, haría lo mismo" (Tolstói, 2000, p. 413).

$Y$ sin embargo, luego en el desesperante estado en el que se encontraba, toma cons-

\footnotetext{
${ }^{26}$ "All Tolstoy's mastery of time, space and language come together in a single moment in the middle of the book, when Anna's estranged husband Alexei Karenin, a dry, stiff government minister, and her lover Vronsky, a handsome young cavalry officer, meet beside the bed where Anna lies gravely ill after giving birth to Vronsky's child. Grief-stricken and ashamed, Vronsky is covering his face with his hands; Anna orders her husband, who is also weeping, to pull the hands away and expose her lover's face. With that gesture, Anna effects a reversal in the status of the two men. Vronsky, who had despised Karenin because he wouldn't fight a duel, is now humiliated and dishonoured; Karenin, flooded with forgiveness for everyone, wins back Anna's respect. In that moment of time, with Anna seemingly dying, the transformation is quite real. But time shifts, and the old reality comes back. Anna gets better and hates Karenin more than ever for his forgiveness. Vronsky restores his honour by shooting himself (he misses). The arc of Anna's destruction resumes. In the novel there are no turning points, only points, and characters travelling through them". James Meek, 2012. (La traducción es nuestra).
} 
ciencia del arrepentimiento, de la necesidad de perdón, de dejar de ser una pecadora. Le dice a Alejo: "tú no puedes perdonarme. Sé muy bien que no soy digna de tu perdón. Vete, vete, eres demasiado bueno" (Tolstói, 2000, p. 304).

Alejandro Alejandrovitch no tenía previsto perdonar a su mujer (...). Comprendió que había cometido una grave equivocación. Pero esta no consistía en no haber previsto lo que ocurrió, sino en haber ignorado sus propios sentimientos hasta que se enfrentó con la enfermedad de su esposa. Estando de pie junto al lecho de Ana, se había dejado llevar, por primera vez en su vida, de la compasión que le inspiraba los sufrimientos ajenos, sentimientos de los que hasta entonces se había avergonzado como de una debilidad que le perjudicaba. La piedad que sintió ante la enferma, el arrepentimiento que experimentó por haber deseado su muerte $y$, sobre todo, la alegría que le invadió en el momento de perdonarla generosamente, dieron lugar no sólo a que los sufrimientos se convirtieran para él en una satisfacción, sino a que gozara de una tranquilidad de conciencia y de una paz espiritual que no había conocido anteriormente (Tolstói, 2000, p. 311).

Hasta el momento de enfrentarse con la situación sumamente delicada de su esposa, Alejo se había avergonzado de sus sentimientos de compasión, de amor, de ternura. Pero en el momento de perdonarla, no solo se sintió satisfecho sino en paz. La paz y la tranquilidad de haber hecho lo correcto $y$, curiosamente, no solo lo "justo".

Notó que aquello que había sido hasta entonces el manantial de sus pesares se convirtió de súbito en una fuente de alegría interior, ya que aquello que antes, cuando censuraba, criticaba y odiaba, se le antojaban problemas sin solución, ahora, desde que había aprendido a perdonar y amar, eran cuestiones de una sencillez extrema y de una claridad diáfana (Tolstói, 2000, p. 311).

\section{LOS SUICIDIOS EN LA OBRA}

El pensamiento del suicidio es un poderoso medio de consuelo: con él se logra soportar más de una mala noche (Nietzsche, 2008, p. 94)

El primer suicidio que aparece en la obra se da en el momento en el que Ana llega a Moscú. "Esto es un mal presagio" (Tolstói, 2000, p. 58), nos adelanta. Si bien no se nos narran los motivos que llevaron a este personaje, que no conocimos pero que perdimos al suicidarse, se nos presenta la oportunidad de ver las reacciones de los personajes ante el suicidio. Por supuesto, lo primero que se oye en la estación de tren son los gritos y el horror. Pero también se introduce la frase: "... yo creo que no hay mejor muerte que esa. Ha sido instantánea" (Tolstói, 2000, p. 58).

No es fácil coincidir con quien dice eso. Es cierto que lo que comúnmente se llama "buena muerte" es aquella en la que no hay dolor ni sufrimiento. Sin embargo, consideramos que debería ser acompañada, sentida, rezada.

El primer suicidio parece no ser de tanta importancia, hasta que llegamos a la última resolución de Ana:

¿A dónde huir, Dios mío?" (...) De pronto acudió a su mente el recuerdo de aquel hombre que murió bajo las ruedas de un tren en la estación de Moscú el día que ella conoció a Wronsky, y entonces se dijo que había encontrado la solución (Tolstói, 2000, p. 606). 
En el caso de Wronsky,

... había pasado por una situación verdaderamente embarazosa cuyo momento más terrible le pareció aquél en que Alejo Alejandrovitch apartó las manos de su rostro, que ardía de vergüenza. (...) Muchos se pegan un tiro para no morir de vergüenza -murmuró. Se acercó a la puerta (...) sacó el revólver, (...) Y, apoyando el cañón del revólver en el lado izquierdo del pecho y haciendo una fuerte contracción con la mano como si quisiera cerrar el puño, apretó el gatillo (Tolstói, 2000, p. 310).

¿Qué hace sentir avergonzado a Wronsky? ¿Será que lo hayan perdonado? Como señalábamos anteriormente, el ser perdonado le recordó sus propias bajezas, su humanidad corrupta y su mal accionar. Si bien Wronsky logra salvarse y no muere en este momento, su tentativa no deja de ser de suma importancia para terminar de entender lo que le sucede a nuestro personaje a raíz de haberle sido otorgado el perdón. No quiere vivir conociendo que es imperfecto, que es inferior, que necesita ser perdonado.

Indudablemente, el suicidio más importante de la obra es el de la misma Ana Karenina. Ella muere porque no podía aguantar más el sufrimiento, porque no encuentra más salida en ese laberinto de culpa. Porque siente que arruinó su vida para siempre. Desprecia a su amante, no quiere a su hija, simplemente quisiera que nada hubiera sucedido.

La última frase de Ana es muy simbólica:"Señor, perdón por todo" (Tolstói, 2000, p. 607). Ana vuelve a pedir perdón, pero esta vez al Juez más misericordioso. Koehler escribió: "el nombre de Yahvé es Misericordia" (1974, c. 1317).

Es importante en este punto diferenciar el perdón humano del perdón divino: mientras que el terrenal puede hacerles bien a las partes, el perdón de Dios borra totalmente la falta cometida. Cuando Dios nos perdona, volvemos a estar plenos, en íntima relación con él.

\begin{abstract}
Durante su vida pública, Jesús no sólo perdonó los pecados, también manifestó el efecto de este perdón: a los pecadores que son perdonados los vuelve a integrar en la comunidad del pueblo de Dios, de donde el pecado los había alejado o incluso excluido. Un signo manifiesto de ello es el hecho de que Jesús admite a los pecadores a su mesa, más aún, Él mismo se sienta a su mesa, gesto que expresa de manera conmovedora, a la vez, el perdón de Dios y el retorno al seno del pueblo de $\operatorname{Dios}^{27}$.
\end{abstract}

Se nos sugiere, por último, que incluso un personaje como Levine podía llegar a sentirse atraído por el suicidio. En esta frase vemos por qué: "Así vivía Levine, siguiendo un camino recto y claro, y sin entrever la posibilidad de hallar explicación al misterio de la existencia, misterio que le atormentaba hasta el punto de que había llegado a temer suicidarse" (Tolstói, 2000, p. 631).

Lo que podía llevarlo al suicidio no era ni más ni menos que la falta de sentido. Ser consciente del misterio, pero sin poder comprenderlo.

\section{CONCLUSIONES}

Tolstói, por medio de Levine, nos muestra esto:

... vivir para Dios...Vivir para la verdad... Vivir para el alma... Estas palabras hallaron eco en su corazón, y pensamientos confusos pero fecundos, surgiendo de algún rincón

${ }^{27}$ Catecismo de la Iglesia Católica. 2.a parte, 2. a sección, 2. ${ }^{\circ}$ capítulo, artículo 4. ${ }^{\circ}, 1443$. 
profundo y misterioso de su cerebro, donde habían permanecido ocultos, llenaron su mente y empezaron a centellar con luz cegadora (Tolstói, 2000, p. 634).

Levine que, como señalamos anteriormente, estuvo toda la obra en su propia búsqueda por el sentido de la vida, se plantea al final:

... yo buscaba una solución que mi pensamiento no me podía dar porque ella es superior a las facultades de la mente; sólo la vida, con el conocimiento innato del bien y del mal, podía darme la respuesta. Este conocimiento se me otorgó con el ser como a todos los mortales; ni lo he adquirido ni me habría sido posible dar con la pista que me permitiera llegar a él; el razonamiento no me habría demostrado jamás que debo amar al prójimo en vez de odiarlo a muerte. Cuando me lo enseñaron siendo niño, lo creí fácilmente porque ya lo sabía. En la razón no hallaremos nada que nos induzca a amar al prójimo, porque este amor no es producto de la mente (Tolstói, 2000, p. 636).

Algo similar decía Tolstói a su hijo en la cita del principio del artículo. El sentido de la vida, así como el bien, la verdad, el amor, no se desprenden del pensar humano, no podemos crear el bien ni darnos a nosotros mismos un sentido; se nos otorga junto con el ser. Levine, que había sido toda su vida un buen hombre, entiende en su adultez y tras mucho pensamiento que estos nos son dados. Los últimos dos párrafos de Ana Karenina son extraordinarios y merecen un lugar en este trabajo:

Este nuevo sentimiento, contra lo que yo creía, no me ha cambiado, ni deslumbrado, ni me ha hecho feliz, del mismo modo que no me sentí otro hombre al saber que era padre. Pero es un sentimiento que ha nacido en mi alma del dolor y que ha echado raíces. Y esto no es otra cosa que la fe, sea cual fuere el nombre que yo quiera darle. Seguramente seguiré indignándome contra el cochero, discutiendo en vano, expresando inoportunamente mis ideas; seguramente veré durante toda mi vida que se levanta una barrera entre el santuario de mi alma y el alma de los demás, incluso de mi mujer, a la que seguiré echando la culpa de mis zozobras para arrepentirme al instante. Seguiré rezando sin comprender por qué rezo. Pero es lo cierto que mi vida íntima posee hoy una libertad de movimientos que no tenía antes. Ahora ya no será un juguete del azar; cada minuto de mi existencia tendrá desde este momento un profundo sentido que podré imprimir en todos mis actos: el sentido del bien (Tolstói, 2000, p. 651).

Podemos conjeturar, sin que nos lo señale de esta forma, que lo mismo le sucede a Alejo. Dejó de ser el hombre justo, el "hermano mayor", y comenzó a ser como el Padre, misericordioso, amoroso.

En una carta a Serguéi Alexándrovich Rachinski, en el año 1878 (poco después de la publicación de Ana Karenina), Tolstói le escribe:

Su opinión sobre Ana Karenina me parece errónea. Al contrario, estoy orgulloso de la arquitectura: las bóvedas están unidas de tal manera que no se ven las trabazones. Eso fue de lo que más me preocupé. Lo que une la construcción no es el argumento ni las amistades entre los personajes, sino el vínculo interno. (...) Me temo que cuando leyó la novela no reparó en el contenido interior. No pondría objeción en que alguien dijera "que me veut cette sonate" [¿qué tiene que ver conmigo esta sonata?], pero si usted 
desea verdaderamente hablar de falta de vínculo, en ese caso no puedo evitar decirle que no lo está buscando en el lugar adecuado, o entendemos de manera distinta la palabra vínculo. Pero lo que yo entiendo por vínculo - lo que hizo que este trabajo fuera importante para mí-, ese vínculo está ahí, búsquelo bien, lo va a encontrar (Tolstói, 2008, p. 387) $)^{28}$.

Como pudimos ver, lo que hace de esta obra algo maravilloso no son solo las amistades o amores entre los personajes, las bellísimas descripciones, sino quizás, ante todo, lo que a mi juicio es su enseñanza más profunda. Esta es, entonces, el perdón, los límites de los hombres ante él, su vinculación con la justicia. El suicidio como consecuencia posible de estar fuera del camino del bien, de una cierta incapacidad para aceptar el regalo del perdón y librarse consecuentemente de la culpa que atormenta. Las historias de los personajes, las relaciones, las descripciones, sirven como guías para llevarnos a entender estas importantísimas cuestiones.

Es una obra que merece ser leída y releída cuantas veces sea necesario para que sus ideas de justicia, de bien, de verdad, de amor y de misericordia nos penetren el alma y, así, lleguemos a cumplir el deseo de Tolstói de hacer que todos logremos"contribuir de todas las maneras posibles al desarrollo armónico de lo existente" (Tolstói, 2011, p. 17).

\section{REFERENCIAS BIBLIOGRÁFICAS}

Aristóteles (1948). Moral a Eudemo. Buenos Aires, Argentina: Colección Austral.

Babushkina. I. S. (2016). El problema de la elec- ción de camino, Ministerio de Educación y Ciencia de la Federación de Rusia. Universidad Federal de los Urales, Instituto de Filología, Cultura y Comunicación Intercultural - Departamento de Literatura. Recuperado de http://elar.uspu.ru/bitstream/ uspu/3958/1/20Babuskina.pdf (consultada en agosto de 2018).

Biblia de Jerusalén. Descleé de Brouwer. Bilbao, 2009.

Burggraf, J. (2007). "El arte de perdonar". Instituto de Estudios Superiores de la Familia (IESF) de la Universitat Internacional de Catalunya. Recuperado de http://www.llar.eu/ files/Convivir_en_el_matrimonio.pdf

Catecismo de la Iglesia Católica (1993). Madrid, España: Conferencia Episcopal Argentina.

De Martini, S. M. Á. (2013). Misericordia y justicia. Buenos Aires, Argentina: Educa.

Fraile, G. (1976). Historia de la Filosofía. Madrid, España: BAC.

Gómez Robledo, A. (1982). Meditación sobre la justicia. Ciudad de México, México: Fondo de Cultura Económica.

Hesíodo (2006). Los trabajos y los días. Madrid, España: Gredos.

Jaeger, W. (2012). Paideia: Ios ideales de la cultura griega. Ciudad de México, México: Fondo de Cultura Económica.

Juan Pablo II (1980) Dives in misericordia. Recuperado de: http://www.vatican.va/ content/john-paul-ii/es/encyclicals/documents/hf_jp-ii_enc_30111980_dives-inmisericordia.html

Koehler, T. (1974). "Miséricorde". En Dictionnaire de Spiritualité, T. X. París, Francia: Beauchesne.

Marzie, Y. (2007). Роль религии в духовном возрождении литературных

героин Л.Т. Толстого [El papel de la religión en el

${ }^{28}$ Cf. Nelly Vélez, "La arquitectura invisible de Anna Karénina de Leo Tolstói”. Revista Pensamiento y Cultura 21(1): $203-220$. Universidad de la Sabana, 2009. 
renacimiento espiritual en la literatura de L.T. Tolstói.] Pazhuhesh-e Zabanha-ye Khareji, No. 35, Special Issue, Rusia, 2007, pp.91-101. Recuperado de https://jor.ut.ac.ir/article_18071_ bfe83c57fcdec5289da5326584283b75.pdf (consultado en agosto de 2018).

Meek, J. (2012). Rereading Anna Karenina by Leo Tolstoy. Recuperado de https://www. theguardian.com/books/2012/aug/31/rereading-anna-karenina-james-meek (consultado en mayo de 2018).

Nietzsche, F. (2008). Más allá del bien y del mal. Buenos Aires, Argentina: Editorial Centro Editor de Cultura.

Nietzsche, F. (2012). Nietzsche, todos los aforismos. Buenos Aires, Argentina: Leviatán.

Pétré, H. (1948). Cáritas. Étude sur le vocabulaire latin de la charité chrétienne. Lovania, Francia: Spicilegium sacrum lovaniense.

Sáenz, A. (1995). Las parábolas del Evangelio según los Padres de la Iglesia. La misericordia de Dios. Buenos Aires, Argentina. Gladius.

San Agustín de Hipona. (1975). La ciudad de Dios. Ciudad de México, México: Porrúa.

San Francisco de Sales. (1999). Tratado del amor de Dios. Madrid, España: Edibesa.

Santo Tomás de Aquino. (1959) Suma Teológica. Madrid, España. BAC. Comentario al Salmo 50.

Recuperado de http://hosted.desales.edu/w4/ philtheo/loughlin/ATP/Psalm_50.html

Samaan, I. Penitencia y confesión. Recuperado de http://iglesiaortodoxa.org.mx/informacion/1111/11/penitencia-y-confesion/ (consultada en enero de 2018).

Séneca. “De la clemencia”, L. II, VII, 1. En Cicerón y Séneca. Tratados morales. Buenos Aires, Argentina: W. M. Jackson, 1949.

Sófocles (2012). Edipo Rey. Obras Selectas. Madrid, España: Edimat.

Testa, E. (1981). "La misericordia nell'Antico Testamento". AA.VV.: Dives in misericordia. Commento all'enciclica di Giovanni Paolo II. Pontificia Universitas Urbaniana, Paideia.

Tolstói, L. (1952). Ana Karenina. Madrid, España: Aguilar.

Tolstói, L. (2000). Ana Karenina. Barcelona, España: Sol.

Tolstói, L. (2004). La sonata a Kreutzer. Madrid, España: Alianza.

Tolstói, L. (2008). Correspondencia. Barcelona, España: Acantilado. Tolstói, L. (2011). Diarios (1847-1894). Barcelona, España: Acantilado.

Tolstói, L. (2014). Анна Каренина. АзБУКА (AzBUKA). San Petersburgo, Rusia.

Vélez, N. (2009). "La arquitectura invisible de Anna Karénina de Leo Tolstói". Revista Pensamiento y Cultura 21(1): 203-220. Universidad de la Sabana. ProQuest Ebook Central. Recuperado de https://ebookcentral.proquest.com/lib/sibucasp/detail. action?docID=3194455.

Zecchin de Fasano, G. C. (2014). "El concepto de Eunomía: ¿Odisea en Solón?". Recuperado de http://www.fuenstesmemoria.fahce. unlp.edu.ar/art_revistas/pr.4220/pr.4220. pdf (consultada en marzo 2018). 